\title{
A Study on Pitfall Trapping of Darkling Beetles (Coleoptera: Tenebrionidae)
}

\author{
K. N. Muniswamy Gowda*, R. Vinay Kumar and O. R. Nataraju \\ College of Agriculture, Hassan, Karnataka, India \\ *Corresponding author
}

A B S T R A C T

K e y w o r d s
Tenebrionid beetles,
Pitfall trap catch,
Weather factors
Article Info
Accepted:
$\begin{aligned} & \text { 30 May } 2020 \\ & \text { Available Online: } \\ & \text { 10 June } 2020\end{aligned}$

\section{Introduction}

Tenebrionidae is one of the largest families in the animal kingdom containing more than 18000 species in the world (Watt, 1974) of which 300 species are recorded from India (Lefroy, 1909). Beetles play significant roles in most ecosystems (Ehrenfeld, 1988). Prominent epigeal examples are the tenebrionids that play a relatively major role in tropical and subtropical drylands, more so with increasing aridity (Henschel et al., 2010). Since the inventorying of biodiversity is the first step in any conservation programme. Among the ground dwelling organisms, tenebrionids are relatively abundant, large, readily captured in pitfall traps and the most easily identified. Communities of these beetles integrate factors such as the availability of detritus, plant cover and various soil characteristics like moisture, hardness and grain size composition. Therefore, tenebrionids are considered as sensitive indicators of biodiversity change due to habitat loss and degradation (Parenzee, 2001). Tenebrionids may generally be described as rather slow moving, black, flightless beetles. Adults and larvae are considered as detritivorous (Wallwork, 1982), although adults have been noticed feeding upon carrion (Mckinnerney, 1978) and dung (Buxton, 1924) and some larvae are root feeders (Rafes, 1960). Tenebrionids may play an important role in detritus cycling in 
ecosystems (Draney, 1993). Long term monitoring programme of their population can provide valuable insights into how environmental changes affect organisms (Henschel et al., 2003). Pitfall traps are useful in studying seasonal occurrence and relative abundance in a particular habitat. Presumably nothing is known about their ecology, diversity and the important role played by these beetles in the ecosystem. Hence, a study was conducted during January 2018 to December 2019 at Agricultural College, Karekere, Hassan, Karnataka to find out the occurrence of the tenebrionids in different habitats, their relative abundance and influence of weather factors on pitfall trap catches.

\section{Materials and Methods}

This study was carried out at three different sites, all situated at Agricultural College, Karekere, Hassan, Karnataka such as agroforest, ragi field and grassland. Each habitat was measured to be 10,000 sq.m., andthe selected habitat areas were represented their own characteristic features being surrounded by areas of their own habitat nature. Empty tins of $10 \mathrm{~cm}$ diameter and $25 \mathrm{~cm}$ deep were used as pitfall traps. The trap was buried into the soil upto the rim and funnel of same diameter was placed above this to prevent the escape of beetles trapped. The trapped beetles were recorded once in every week. Traps were run from first week of January 2018 to last week of December 2019. The weekly log (catch +1) were correlated with weather factors namely mean minimum temperature, mean maximum temperature, mean saturation vapour pressure deficit and total rainfall for the respective weeks. A multiple linear regression model $y=a+b_{1} X_{1}+b_{2} X_{2}+b_{3} X_{3}$ $+\mathrm{b}_{4} \mathrm{X}_{4}$ (where $\mathrm{y}, \mathrm{X}_{1}, \mathrm{X}_{2}, \mathrm{X}_{3}$ and $\mathrm{X}_{4}$ correspond to $\log$ (catch +1 ), mean maximum temperature $\left({ }^{\mathrm{o}} \mathrm{c}\right)$, mean minimum temperature $\left({ }^{\mathrm{c}} \mathrm{c}\right)$, mean saturation vapour pressure deficit
(\%) and total rainfall $(\mathrm{mm})$ respectively of a week was obtained.

\section{Results and Discussion}

During the study seventeen species of tenebrionids belonging to eight genera were collected in pitfall traps in different habitats. The number of beetles collected in different habitatsis given in Table.

Gonocephalum oblongum, Pachycera coromandelensis, Rhytinota laevipennis and Scleronreitteri were the most commonly found species in pitfall traps. The highest number of beetles were trapped in grassland (130) followed by traps in ragi field (105) and agro-forest (52).

The activity of tenebrionids was found to have relation with undisturbed habitat. Cepeda (1989) reported that soil temperature and moisture regime regulated the life cycles of most of the species living in the area and not vegetation of that area. The number of beetles seemed to be inversely related to the degree of disturbance and permanency of habitats. Accordingly, maximum number of beetles was recorded in the grassland followed by ragi field and agro-forest.

The tenebrionid beetles showed habitat preference. Menearchussp $\mathrm{s}_{1}$ and Menearchus $\mathrm{sp}_{2}$ were limited only to ragi field whereas Pachycerasp, Rhytinota laticollis, Rhytinota $\mathrm{sp}_{1}$ and Rhytinota $\mathrm{sp}_{2}$ were restricted only to grassland. No beetle of these species was found in other habitats. This may be because of the propensity of these beetles to thick vegetation.

Some species viz., Gonocephalum spp., Pachycera coromandelensis, Pachycera pondicheryina, Rhytinota laevipennis and Scleronreitteri were found in all habitats. This indicates that these species are capable of 
existing in a wide range of habitats (Aldryhim et. al., 1992).

Pachycera coromandelensis was also collected in more number (40) at ragi field than at other habitats. More number of Rhytinota laevipennis (45) and Scleronreitteri (25) were collected in grassland and agroforest respectively.

The highest number of tenebrionids were caught during June and same trend continued till the end of October. The good vegetation during rainy season which harboured many insects and activity of tenebrionids coincided here. The catch in traps started declining from first week of November. abundance of different species in different habitats. Rhytinota laevipennis and Scleronreitteri were found abundantly in grassland and agro-forest, respectively indicating the affinity of beetles to vegetation and soil moisture.

Weather factors such as saturation vapour pressure deficit and rainfall were significantly correlated with pitfall trap catches. They had correlation coefficient of +0.29 and +0.50 respectively. The rainfall which explained 24 percent variance had influence on trap catches. All the weather factors accounted for 21.5 per cent fluctuations and could be explained by linear regression model $\mathrm{y}=$ $1.46+0.07 \mathrm{X}_{1}+0.09 \mathrm{X}_{2}+0.04 \mathrm{X}_{3}+0.09 \mathrm{X}_{4}$.

The continuous pitfall trapping gave relative

Table.1 Tenebrionids trapped in pitfall traps at different habitats

\begin{tabular}{|c|c|c|c|c|}
\hline \multirow{2}{*}{$\begin{array}{l}\text { Sl. } \\
\text { No. }\end{array}$} & \multirow[t]{2}{*}{ Species } & \multicolumn{3}{|c|}{ Number of beetles trapped in } \\
\hline & & Agro-forest & Ragi field & Grass land \\
\hline 1 & Gonocephalum oblongum & 10 & 13 & 8 \\
\hline 2 & Gonocephalum sp.1 & 1 & 2 & 4 \\
\hline 3 & Gonocephalum sp.2 & 2 & 3 & 5 \\
\hline 4 & Himatismus fasciculatus (Fabricius) & - & 2 & 3 \\
\hline 5 & $\begin{array}{l}\text { Leichenum canaliculatum } \\
\text { (Fabricius) }\end{array}$ & - & 1 & 2 \\
\hline 6 & $\begin{array}{l}\text { Menearchus arcuatus } \\
\text { (Audinetserville) }\end{array}$ & - & 10 & 3 \\
\hline 7 & Menearchus $\mathrm{sp}_{.1}$ & - & 2 & - \\
\hline 8 & Menearchus sp.2 & - & 3 & - \\
\hline 9 & Notocorax crenatus (Fabricius) & 7 & - & 1 \\
\hline 10 & Pachycera coromandelensis (Koch) & 3 & 40 & 2 \\
\hline 11 & Pachycerapondicheryina (Koch) & 2 & 8 & 3 \\
\hline 12 & Pachycera sp. & - & - & 2 \\
\hline 13 & Rhytinota laevipennisFairmaire & 2 & 6 & 45 \\
\hline 14 & Rhytinota laticollis (Schaufuss) & - & - & 2 \\
\hline 15 & Rhytinota sp.1 & - & - & 5 \\
\hline 16 & Rhytinota sp.2 & - & - & 8 \\
\hline \multirow[t]{2}{*}{17} & Scleronreitteri Gebien & 25 & 15 & 10 \\
\hline & Total & 52 & 105 & 130 \\
\hline
\end{tabular}




\section{References}

Aldryhim, Y. N., C. W. Mills III and A. S. Aldawood, 1992, Ecological distribution and seasonality of darkling beetles (Coleoptera: Tenebrionidae) in the central region of Saudi Arabia. Journal of Arid Environments, 23: 415-422.

Buxton, P. A., 1924, Habits of some Tenebrionid beetles. Entomol. Mon. Mag., 60: 3-7.

Cepeda-Pizarro Jorge-G., 1989, Temporal activity of epigeous tenebrionids (Coleoptera) and their relationship with the shrubby vegetation in arid ecosystem of Chile. Revista-chilenade-Historia- Natural (Chile), 62 (1): 115-125.

Draney, M. L., 1993, The subelytral cavity of desert Tenebrionids Florida Entomologist, 76 (4): 1-11.

Ehrenfeld, D., 1988, Why you put a value on biodiversity, 521: 212-216.

Henschel, J. R., C. Grohmann V. Siteketa and K. E. Linsensnair, 2010, Monitoring Tenebrionid beetle biodiversity in Namibia African study monographs, suppl., 40: 91102.
Henschel, J. R., V. Myuleni, J. Pallett and M. K. Seely, 2003, The surface-dwelling arthropodfauna of Gobabeb with a description of the longterm pitfall trapping project. Journal Namibia scientific society, 51: 65-92.

Lefroy, H. M., 1909, Coleoptera. Indian Insecta life, today and tomorrow's printers and publishers, New Delhi, pp: 335-339.

Mckinnerne, Y. M., 1978, Carrion communities in the northern Chihuahuan desert. South west Nat., 23: 563-576.

Parenzee, L., 2001, Use of Tenebrionid beetles as indicators of habitat quality.M.Sc. Thesis: University of the Witwaterstand, Johannesburg.

Rafes, P. M., 1960, The life forms of insects inhabitaing the Naryn sands of the semi desert Transvolga region. Entomol. Rev., 38: 19-31.

Wallwork, J. A., 1982, Desert soil fauna. Praeger pub. NY., pp: 296.

Watt, J. C., 1974, A revised sub-family classification of Tenebrionidae (Coleoptera) N. Z. J. Zool., 1: 381-452.

\section{How to cite this article:}

Muniswamy Gowda, K. N., R. Vinay Kumar and Nataraju, O. R. 2020. A Study on Pitfall Trapping of Darkling Beetles (Coleoptera: Tenebrionidae). Int.J.Curr.Microbiol.App.Sci. 9(06): 4090-4093. doi: https://doi.org/10.20546/ijcmas.2020.906.479 